\title{
Elastic Characterization of Glass by Modal Analysis
}

\author{
Mohd Hilman Mohd Akil Tan, Nur Liyana Tajul Lile, Fauziah Mat, Sazali Yaacob \\ School of Mechatronics Engineering, Universiti Malaysia Perlis, Perlis, Malaysia \\ E-mail: hilmanakil@yahoo.com,liyanatajul@unimap.edu.my,fauziah@unimap.edu.my,sazali22@yahoo.com
}

\begin{abstract}
Modal analysis is the study of dynamic characteristic of structures induced by vibrational excitation. Under modal excitation, three important parameters namely natural frequency, damping ratio and mode shape associated with the structural properties are acquired. This paper presents an experimental investigation of glass by experimental modal analysis. The specimen is excited by an impact hammer to perform resonant vibration where the characteristics of the resonance are acquired. One most important characteristic is the natural frequency where it is known that different material having undergone resonant vibration exhibit different specific natural frequencies to it. The natural frequencies are used as the parameters of determining the structural properties of the glass. The modal analysis is done using the LMS instruments and software where Frequency Response Function (FRF) measurement technique is employed in determining the natural frequencies. The structural properties are established based on the obtained natural frequencies and geometries of the materials using the expression from available literature. The results are then compared with the theoretical values for verification.
\end{abstract}

Keywords - Modal analysis; Resonant vibration; Natural frequency; Nondestructive testing; FRF measurement; Glass; Young's modulus.

\section{INTRODUCTION}

In industrial context, having the right material for the right structural purpose is vital in order to ensure the safety and reliability of the structure constructed. The knowledge of material properties is important especially in the field of failure analysis where catastrophic and cascading engineering breakdown could be prevented. Thus, various research have been done in order to explore more about material properties and behaviours so that the materials could be utilized to their utmost potential without the occurrence of such damages.

In order to characterize the properties of materials, the materials need to be probed by certain tests and the responses of the materials from such probing and testing would be used as the parameters in order to determine the properties of the materials.

There are generally two types of test; destructive or nondestructive testing. A destructive test would leave the specimens tested no longer usable for further testing and often require specific shaped and sized cutting of the specimens. One example of such test is the tensile testing of materials by universal testing machine which require the specimens to be tested to have dog bone shape.

Nondestructive testing on the other hand is a test which could be done repetitively on the same specimen as it does not alter the subjected specimens being tested. Most of the testing could be done on specimens in varied forms of shape and measurement. One example of such test is the experimental modal analysis.

Modal analysis is the study of dynamic characteristic of structures induced by vibrational excitation. The responses from the excitation are referred as modal parameters. There are three types of modal parameters; natural frequency, mode shape and damping ratio. The values and changes in these parameters signify the values and changes in the physical properties of materials. Therefore, these parameters play imperative roles in classifying the materials accordingly to their properties [1].

ASTM E 1876-09 [2] provided the procedures for determining elastic properties from the measured impulse excitation of vibration. However the standard only applies to specimens with structures of beams, rods and disks.

As highlighted in [3], simple structures like beam and rod are easier for direct determination of elastic constants from modal testing to be applied compare to complex structures like plates and shells. Various research have been done for determination of elastic properties of rectangular plates from modal vibration technique [5-9]. The results are fairly good but require complicated procedures which involve initial estimation of iteration and optimization process.

This paper presents the modal analysis of glass square plate for determination of elastic constants $\mathrm{E}$ and $\mathrm{v}$ based on the procedure presented in [4]. The results then compared to 
the theoretical value to evaluate the precision of such procedure

\section{EXPERIMENTAL MODAL ANALYSIS}

The experimental modal analysis was conducted based on the impulse excitation technique which employs the single fixed output as the reference. A roving hammer having a load cell attached to its head for input force measurement is used as the impulse exciter while an accelerometer is used to measure the responses acceleration at fixed point and direction. This experimental technique which is commonly known as impact hammer testing is widely favoured as a method of modal testing because it is economical, fast and undemanding in terms of resonance investigation of a structure [10].

The impact hammer test was carried out using the Dynamic Application Group (DAG) Technologies (Malaysia) Sdn. Bhd. [11] instruments using the LMS international [12] software where frequency response function (FRF) measurement technique is employed in extracting the natural frequencies

The specimen used in the experiment is a glass square plate having dimension of $250 \mathrm{~mm} \times 250 \mathrm{~mm} \times 3 \mathrm{~mm}$. The plate was marked with nine nodes on the surface acting as the reference points for the impact testing input force as depicted in Fig. 1. The glass used as the specimen is the ordinary sheet glass normally used for windows making.

The specimen was impacted to nine different nodes which were already allocated on the surface of the glass. For each node, the FRF curve was plotted so that the observation of resonant frequency behavior could be performed thoroughly. The natural frequencies of the plate were then determined from the accumulation of FRF curve behavior of all nodes along with corresponding mode shapes and damping ratios.

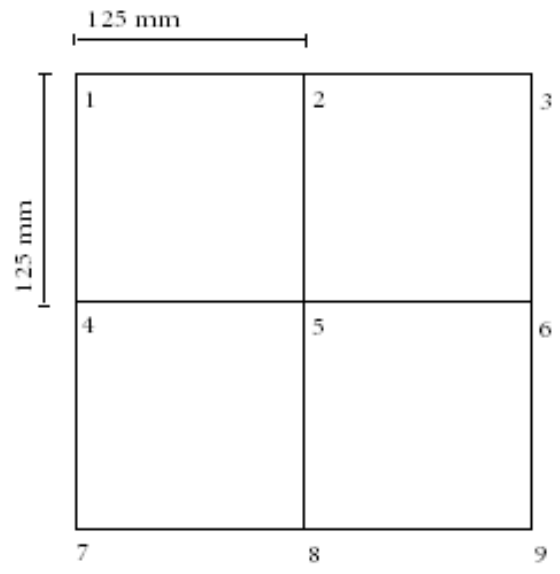

Fig 1. Specimen with nine nodes position on the plate surface

The range of frequencies is limited between $99.68 \mathrm{~Hz}$ to $511 \mathrm{~Hz}$. This is due to the fact that the frequencies existed below $100 \mathrm{~Hz}$ is of the normal rigid body mode thus not applicable for the vibrational modal analysis.

Careful observation should be done in determining the desired natural frequencies where all FRF of every node should be studied because a peak of natural frequency could appear in one node but not the other as depicted in Fig. 2-3. The selection of the right frequencies is the essential step in determining the other values of corresponding modal parameters as damping ratios and mode shapes are directly dependent of the frequencies selected.

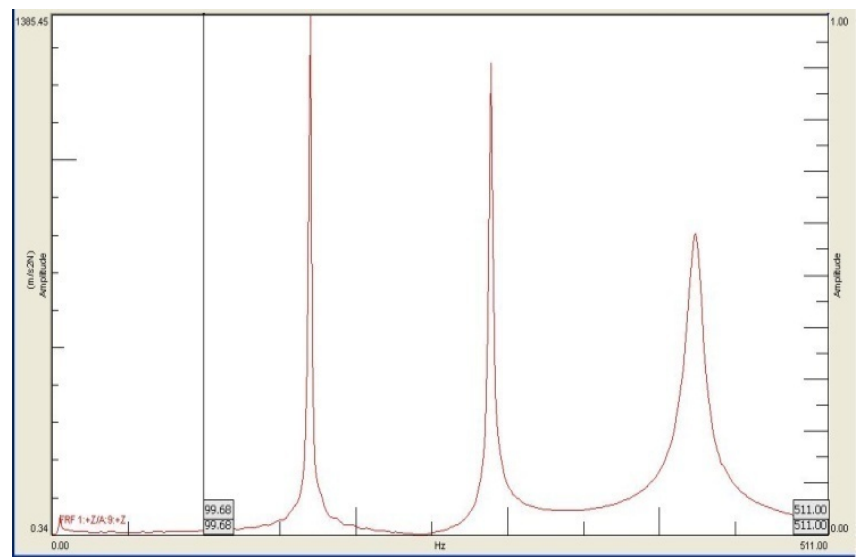

Fig 2. FRF for the first node of glass

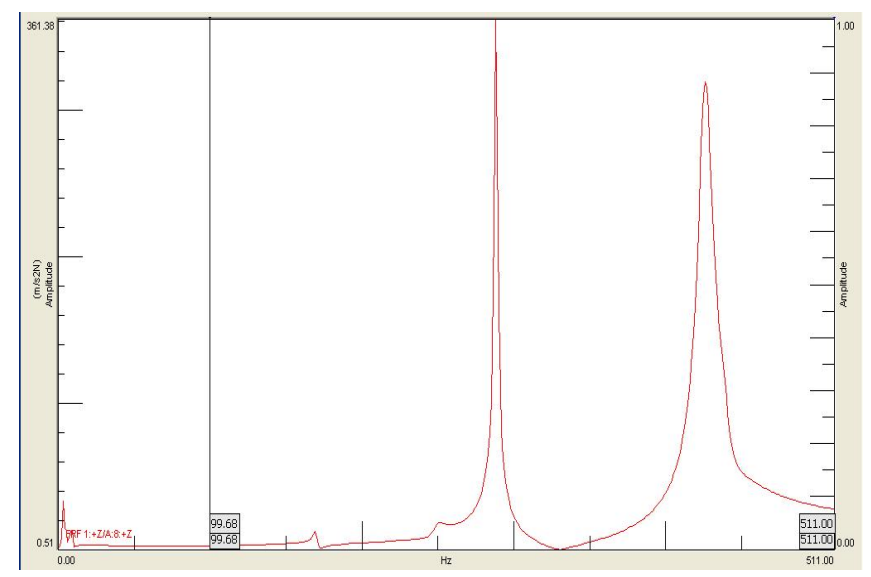

Fig. 3. FRF for the sixth node of glass

The obtained natural frequencies were then exploited for the procedure outlined in [4] using the formula presented in the same paper:

$$
E=\frac{48}{\pi^{2}}\left(\frac{f}{\lambda}\right)^{2} \frac{m a^{3}\left(1-v^{2}\right)}{b t^{3}}
$$

where $E$ and $v$ are the elastic constants, $f$ is the natural frequency, $m$ is the mass of the material, $a$ and $b$ are the length of the sides of the plate, where in this case $a=b, t$ is the thickness, and $\lambda$ is a non-dimensional factor obtained from the table presented in [4] as well.

TABLE I

DIMENSION MASS AND NATURAL FREQUENCIES OF GLASS

\begin{tabular}{lrrrrr}
\hline $\begin{array}{l}\text { Dimensions, } \\
a \times b \times t\left(m^{3}\right)\end{array}$ & $\begin{array}{r}\text { Mass, } m \\
(\mathrm{~kg})\end{array}$ & $f_{1}(\mathrm{~Hz})$ & $f_{2}(\mathrm{~Hz})$ & $f_{3}(\mathrm{~Hz})$ & $f_{4}(\mathrm{~Hz})$ \\
\hline \hline $\begin{array}{l}0.25 \times 0.25 \times \\
0.003\end{array}$ & & & & & \\
\hline
\end{tabular}


TABLE II

ELASTIC CONSTANTS OF GLASS

\begin{tabular}{lrrrrrr}
\hline $\begin{array}{l}\text { Frequency ratio, } \\
f_{i} / f_{i}\end{array}$ & & $v$ & $\lambda i$ & $\lambda j$ & $\begin{array}{r}E i \\
(\mathrm{GPa})\end{array}$ & $\begin{array}{r}E j \\
(\mathrm{GPa})\end{array}$ \\
\hline \hline$f_{3} / f_{1}$ & 1.691 & 0.224 & 1.430 & 2.419 & 66.99 & 66.99 \\
$f_{3} / f_{2}$ & 1.232 & 0.293 & 1.993 & 2.456 & 62.59 & 62.58 \\
$f_{4} / f_{3}$ & 1.533 & 0.198 & 2.403 & 3.683 & 68.67 & 68.67 \\
Mean values & & $\mathbf{0 . 2 3 8}$ & & & & $\mathbf{6 6 . 0 8}$ \\
\hline
\end{tabular}

TABLE III

COMPARISON BETWEEN EXPERIMENTAL AND THEORETICAL VALUES

\begin{tabular}{llrr}
\hline \multirow{2}{*}{ Materials } & Parameters & Experimental & Theoretical \\
\hline \hline \multirow{2}{*}{ Glass } & $\mathrm{E}(\mathrm{GPa})$ & 66.08 & $50-90$ \\
& $\mathrm{~V}$ & 0.238 & $0.18-0.3$ \\
\hline
\end{tabular}

From the comparison table between the experimental modal analysis testing and theoretical values, it could be seen that the values for $E$ and $v$ from experiment are within the range of the theoretical ones.

Due to the advantages that this technique has including the ease of use, inexpensive and convenient way of conducting the procedure, it is not a surprise that this technique has been increasingly favoured to be adopted in industries and laboratories. Besides being a nondestructive type of method with great precision, there is a very high probability that the use of such technique would only continue to grow with more research and exploration of how to employ it to future practicability.

\section{CONCLUSIONS}

This paper presented the use of experimental modal analysis technique in determining the elastic constants for glass square plate. It was found that the values obtained from this technique are in great precision with the theoretical values.

For future work, this modal vibration technique which provides the knowledge of natural frequencies relationship to properties of materials would be best integrated with the use of artificial intelligence algorithm system such as artificial neural network especially in the area of pattern recognition where some preliminary works could be done in order to create a system of materials identification for easier assessment of characterization of materials.

\section{NOMENCLATURE}

length $\mathrm{m}$

width

$\mathrm{m}$

thickness

$\mathrm{m}$

mass

Young's modulus

Poisson's ratio

frequency

frequency factor

$\mathrm{kg}$

$\mathrm{Hz}$

\section{ACKNOWLEDGMENT}

We would like to thank The Malaysian Ministry of Higher Education (MOHE) for kindly provided funding for the research through the "Fundamental Research Grant Scheme" (FRGS) NO 9003-00222.

\section{REFERENCES}

[1] Rao V. Dukkipati, J. S. (2004). 'Textbook of Mechanical Vibrations' Prentice-Hall Of India Pvt. Ltd.

[2] ASTM Standard E1876-09, "Standard test method for dynamic Young's modulus, shear modulus, and Poisson's ratio by impulse excitation of vibration," ASTM International, West Conshohocken, PA, 2003, DOI: 10.1520/E1876-09, www.astm.org.

[3] L. Pagnotta, "Recent progress in identification methods for the elastic characterization of materials," International Journal of Mechanics, 2008, Vol. 2, n. 4, pp. 129-140.

[4] M. Alfano, L. Pagnotta, "Determining the elastic properties of isotropic materials by modal vibration testing of rectangular thin plates," Journal of Sound and Vibration, Vol. 293, 2006, pp. 426439.

[5] A.W. Leissa, Vibration of Plates (NASA SP-160), US Government Printing Office, Washington, DC, 1969

[6] M.D. Waller, Vibration of free rectangular plates. Proceedings of the Physical Society, London 72 (1949), pp. 277-285.

[7] F. Moussu, M. Nivoit, Determination of Elastic Constants of Orthotropic Plates By A Modal Analysis/Method of Superposition, Journal of Sound and Vibration, Volume 165, Issue 1, 22 July 1993, pp 149-163.

[8] S.F. Hwang, C.S. Chang, "Determination of elastic constants of materials by vibration testing," Composite Structures, Vol. 49, 2000, pp 183-190.

[9] L.R. Deobald, R. F. Gibson, "Determination of elastic constants oforthotropic plates by modal analysis/Rayleigh-Ritz technique," Journal of Sound and Vibration, Vol. 124, 1988, pp. 269-283.

[10] Brian J. Schwarz \& Mark H. Richardson, 'Experimental Modal Analysis', Application note Vibrant Technology, Inc., (1999)

[11] Dynamic Application Group (DAG) Technologies (Malaysia) Sdn. Bhd, Malaysia, www.dagtech.com.my.

[12] LMS International NV, Belgium, www.lmsintl.com. 